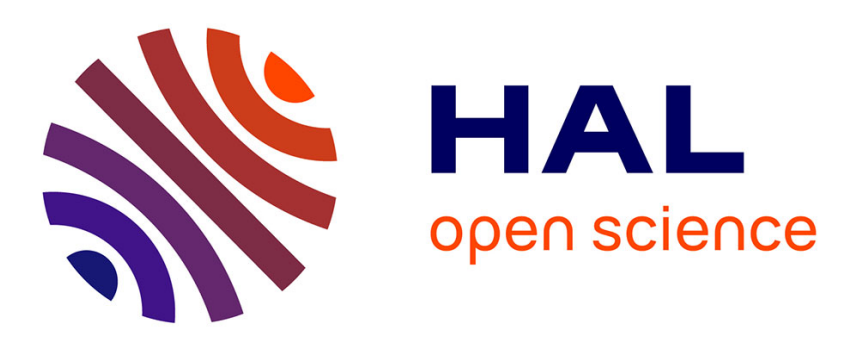

\title{
Peri-operative cardiac biomarker surveillance: a strategy in need of a goal
}

Todd S. Perlstein, Joshua A. Beckman

\section{To cite this version:}

Todd S. Perlstein, Joshua A. Beckman. Peri-operative cardiac biomarker surveillance: a strategy in need of a goal. Vascular Medicine, 2007, 12 (3), pp.211-213. 10.1177/1358863X07083182 . hal00571367

\section{HAL Id: hal-00571367 \\ https://hal.science/hal-00571367}

Submitted on 1 Mar 2011

HAL is a multi-disciplinary open access archive for the deposit and dissemination of scientific research documents, whether they are published or not. The documents may come from teaching and research institutions in France or abroad, or from public or private research centers.
L'archive ouverte pluridisciplinaire HAL, est destinée au dépôt et à la diffusion de documents scientifiques de niveau recherche, publiés ou non, émanant des établissements d'enseignement et de recherche français ou étrangers, des laboratoires publics ou privés. 


\section{Editorial}

\section{Peri-operative cardiac biomarker surveillance: a strategy in need of a goal}

Cardiovascular complications are the leading cause of morbidity and mortality in patients undergoing noncardiac vascular surgery. ${ }^{1}$ There are several elements to the strategy of minimizing this risk. Pre-operatively, determination of the risk of myocardial infarction (MI) and death begins with a comprehensive evaluation of patient-based indicators of cardiac risk and determination of surgery-specific risks such as the degree of hemodynamic stress associated with the procedure. Current data suggest that in patients with stable coronary artery disease undergoing vascular surgery, pre-operative coronary revascularization does not reduce peri-operative risk for cardiovascular events beyond that accomplished by medical therapy. ${ }^{2}$ Despite appropriate assessment and treatment, a small number of patients undergoing vascular surgery will suffer peri-operative MI and/or death.

Several techniques have been developed to monitor patients to discover myocardial ischemia in time to manage it effectively. Intraoperative and postoperative ST-segment monitoring, serial electrocardiography, and serial monitoring of myocardium-specific markers such as troponin or CK-MB have all been recommended as methods to detect myocardial ischemia/ infarction. The most recent ACC/AHA guidelines (published in 2002) recommend that the use of cardiac biomarkers be reserved for patients at high risk and in those patients with clinical, ECG, or hemodynamic evidence of cardiovascular dysfunction. ${ }^{1}$ The appropriate application of these methods, particularly as a surveillance strategy, remains unclear.

Patients with postoperative troponin elevation are at markedly increased risk of having suffered a postoperative MI. The prognostic significance of a postoperative troponin elevation extends to both short-term and long-term mortality, although the data are not uniform. ${ }^{3-6}$ Martinez and colleagues sought to determine the optimal timing of postoperative surveillance troponin determinations in a prospective cohort of 467 high-risk patients requiring non-cardiac surgery, $90 \%$ of which was vascular surgery. ${ }^{7}$ A strategy of measuring surveillance biomarkers on each of postoperative days 1, 2 and 3 appeared to be the most effective strategy, while checking biomarkers on any one day alone was not considered effective.
In this issue of Vascular Medicine, Mohler and colleagues seek to further understand optimal postoperative biomarker surveillance by performing an analysis "to determine if routine serial measurement of [cardiac] biomarkers should be done on the day of and after vascular surgery". ${ }^{8}$ This analysis was performed in a study of 784 patients undergoing vascular surgery and at high risk for cardiovascular events who received a study drug in a placebo-controlled clinical trial of zoniporide therapy to reduce perioperative cardiovascular events, a trial that was discontinued early on the basis of therapeutic futility. ${ }^{9}$ Surveillance cardiac biomarkers were drawn the day of surgery, as well as 24,72 , and 120 hours after surgery, and also 24 hours prior to planned hospital discharge. The goal of the present analysis was to examine the performance characteristics of cardiac troponin I (cTnI) and CK-MB measurements in predicting cardiovascular events after surgery.

In this type of analysis, the definitions utilized are critical and will therefore be elaborated. A positive cardiac biomarker (the exposure of interest) was defined as a cTnI $>3.1 \mathrm{ng} / \mathrm{ml}$ or CK-MB $>$ two times the upper limit of normal with an index $>5 \%$. A cardiovascular event (the outcome of interest) was defined as MI or cardiovascular death occurring up to 30 days after surgery. A new MI was defined as biomarker evidence of myocardial necrosis (CPK index $>5 \%$ or $\mathrm{cTnI} \geq 4.0 \mathrm{ng} / \mathrm{ml}$ ) and one of the following: presence of left bundle-branch block, paced rhythm or non-specific ECG changes, or symptoms consistent with acute myocardial ischemia or acute coronary revascularization procedure. Cardiac death included sudden death, post-resuscitation, definite MI, possible MI, CHF, procedural death, primary intractable serious arrhythmia, or other cardiac death. These definitions were designed for the purposes of the clinical trial within which this analysis is conducted but are not optimal for the purpose of the present study. A consensus (ESC/ACC) definition of acute MI requires a typical rise and fall of cardiac biomarkers and one of the following: (a) ischemic symptoms; (b) development of pathologic $\mathrm{Q}$ waves on ECG; (c) ECG changes indicative of myocardial ischemia (ST elevation or depression); or (d) coronary 
revascularization. ${ }^{10}$ To better understand the present data it would be helpful to know how often the individual criteria for MI were met. For example, how many patients qualified for MI on the basis of a paced rhythm? However, these data were not provided.

Of the 784 patients in the study, 83 had at least one qualifying event. Of the 83 patients with an event, 42 had a positive cTnI and 29 had a positive CK-MB. Of the 699 patients that did not have an event, 64 had a positive cTnI and 20 had a positive CK-MB. Thus, the performance characteristics can be delineated: cTnI had a sensitivity of $51 \%$, a specificity of $91 \%$, a positive predictive value of $40 \%$, and a negative predictive value of $94 \%$; CK-MB had a sensitivity of $35 \%$, a specificity of $97 \%$, a positive predictive value of $59 \%$, and a negative predictive value of $93 \%$. Interpretation of these performance characteristics is confounded by the fact that the definition of the event includes the exposure of interest.

The authors do not clarify the relative importance of sensitivity versus specificity. In other words, is it more important that impending events are detected early, or that they be accurately predicted without excess false alarm? That the authors place more importance on specificity (accurately predicted without excess false alarm) is implied by their choice of a threshold for cTnI of $>3.1 \mathrm{ng} / \mathrm{ml}$. This threshold is highly specific for postoperative infarction, ${ }^{11}$ but the prognostic implications of postoperative cTnI begin at a much lower threshold. ${ }^{5}$ It is therefore not surprising that the results demonstrate better specificity than sensitivity. Despite choosing a threshold that encourages specificity, $50 \%$ more patients with a positive troponin did not have an event than did have an event. It should also be noted that CK-MB was more specific than cTnI in this study, in contrast to previous data and what would be expected based on the biology of these biomarkers. ${ }^{4,11}$ This may be due to chance, but it may be due to the problematic definition of MI used.

The problem with the poor sensitivity and positive predictive value becomes clear once the goal of perioperative cardiac biomarker surveillance is defined. While prognostic information is important, we would argue that, in order to be of significant benefit to patients, the positive biomarkers must stimulate the physician to take an action he/she otherwise would not have. All eligible patients in this study should have been treated with $\beta$-blockade, and despite more limited data, aspirin and $\mathrm{HMG}-\mathrm{CoA}$ reductase inhibitor ('statin') therapy as well. ${ }^{12}$ It seems positive predictive value is therefore of particular importance: which patient needs additional life-saving therapy? The early diagnosis of an acute coronary syndrome might call for escalation of therapy with additional antiplatelet and/or antithrombotic agents and possibly cardiac catheterization with coronary revascularization if indicated. All of these measures need to be applied judiciously in the postoperative setting when the risk of hemorrhagic complication is high. Cardiac TnI had a positive predictive value of $40 \%$ : applying a therapy based on a positive cTnI would therefore be inappropriately applied $60 \%$ of the time. The negative predictive value is nearly 95\%; however, it is not clear what the treating physician might do with this information.

We would recommend postoperative measurement of cardiac biomarkers when there are symptoms or signs suggestive of myocardial ischemia, but would not recommend surveillance measurement in the absence of these. We interpret the data of Mohler and colleagues as supportive of this approach because positive cardiac biomarkers are more likely to occur in patients without than in patients with an MI or cardiovascular death. More data and evidence of benefit from a subsequent treatment adjustment are needed before routine surveillance of cardiac biomarkers postoperatively can be recommended. Prognostic information provides value when intervention may be applied to affect outcome. A new diagnostic strategy requires proof of benefit, not proof of surveillance.

\section{References}

1 Eagle KA, Berger PB, Calkins $\mathrm{H}$ et al. ACC/AHA guideline update for perioperative cardiovascular evaluation for noncardiac surgery - executive summary: a report of the American College of Cardiology/American Heart Association Task Force on Practice Guidelines (Committee to Update the 1996 Guidelines on Perioperative Cardiovascular Evaluation for Noncardiac Surgery). J Am Coll Cardiol 2002; 39: 542-53.

2 McFalls EO, Ward HB, Moritz TE et al. Coronary-artery revascularization before elective major vascular surgery. $N$ Engl $J$ Med 2004; 351: 2795-804.

3 Lee TH, Thomas EJ, Ludwig LE et al. Troponin T as a marker for myocardial ischemia in patients undergoing major noncardiac surgery. Am J Cardiol 1996; 77: 1031-36.

4 Lopez-Jimenez F, Goldman L, Sacks DB et al. Prognostic value of cardiac troponin $\mathrm{T}$ after noncardiac surgery: 6-month follow-up data. J Am Coll Cardiol 1997; 29: 1241-45.

5 Kim LJ, Martinez EA, Faraday N et al. Cardiac troponin I predicts short-term mortality in vascular surgery patients. Circulation 2002; 106: 2366-71.

6 Landesberg G, Shatz V, Akopnik I et al. Association of cardiac troponin, CK-MB, and postoperative myocardial ischemia with long-term survival after major vascular surgery. J Am Coll Cardiol 2003; 42: 1547-54.

7 Martinez EA, Nass CM, Jermyn RM et al. Intermittent cardiac troponin-I screening is an effective means of surveillance for a perioperative myocardial infarction. J Cardiothorac Vasc Anesth 2005; 19: 577-82.

8 Mohler ER, Mantha S, Miller AB et al. Should troponin and creatinine kinase be routinely measured after vascular surgery. Vasc Med 2007; 12: 175-181.

9 Fleisher LA, Newman MF, St Aubin LB et al. Efficacy of zoniporide, an $\mathrm{Na} / \mathrm{H}$ exchange ion inhibitor, for reducing perioperative cardiovascular events in vascular surgery patients. J Cardiothorac Vasc Anesth 2005; 19: 570-76. 
10 Alpert JS, Thygesen K, Antman E, Bassand JP. Myocardial infarction redefined - a consensus document of The Joint European Society of Cardiology/American College of Cardiology Committee for the redefinition of myocardial infarction. J Am Coll Cardiol 2000; 36: 959-69.

11 Adams JE 3rd, Sicard GA, Allen BT et al. Diagnosis of perioperative myocardial infarction with measurement of cardiac troponin I. N Engl J Med 1994; 330: 670-74.

12 Auerbach A, Goldman L. Assessing and reducing the cardiac risk of noncardiac surgery. Circulation 2006; 113: $1361-76$.
Todd S Perlstein and Joshua A Beckman*

Cardiovascular Division Brigham and Women's Hospital 75 Francis Street Boston, MA 02115

*Correspondence: Tel: +1 6177327367 E-mail: jbeckman@partners.org 